\title{
Biomechanical Outcomes Related with Gait in Children with Cerebral Palsy Using Ankle-Foot Orthotic - A Systematic Review
}

\author{
Jéssica Jorge GORDO ${ }^{1, a}$, Paula PASCOAL-FARIA ${ }^{2,3, b}$, \\ Artur MATEUS ${ }^{2,4, c}$, Pedro MOROUÇO ${ }^{2, d}$, Verónica SCHIRIATI ${ }^{5, \mathrm{e}}$, \\ Sandra AMADO $1,2,6, f^{*}$ \\ ${ }^{1}$ School of Health Sciences at the Polytechnic Institute of Leiria, Portugal \\ ${ }^{2}$ Centre for Rapid and Sustainable Product Development, Polytechnic Institute of Leiria, Rua de \\ Portugal, Marinha Grande, 2430-028, Portugal \\ ${ }^{3}$ Department Mathematics, School of Technology and Management, Polytechnic Institute of Leiria, \\ Rua General Norton de Matos, Apartado 4133, 2411-901 Leiria - Portugal, Portugal \\ ${ }^{4}$ Mechanical Engineering Department, School of Technology and Management, Polytechnic \\ Institute of Leiria, Portugal \\ ${ }^{5}$ Division of Medical Sciences, University of Victoria, Victoria, BC, Canada \\ ${ }^{6}$ CIPER-FMH, Centro Interdisciplinar de Estudo de Performance Humana, Faculdade de \\ Motricidade Humana (FMH), Universidade de Lisboa (UL), Lisboa, Portugal. \\ ajessg.294@gmail.com, bpaula.faria@ipleiria.pt, cartur.mateus@ipleiria.pt, \\ dpedro.morouco@ipleiria.pt, 'vschiariti@cw.bc.ca, 'sandra.amado@ipleiria.pt \\ ${ }^{*}$ corresponding author
}

Keywords: Biomechanics, Ankle-Foot Orthotic, gait, cerebral palsy, children

\begin{abstract}
Gait in children with cerebral palsy (CP) is often affected by motor impairments which limit the patient's ability to walk. To improve gait and reduce walking limitations, children with $\mathrm{CP}$ need to use ankle foot orthoses. An orthosis is an externally applied device that is designed and fitted to the body to achieve one or more of the following goals: a) Control biomechanical alignment. b) Correct or accommodate deformity, and 3) Protect and support an injury. This systematic review aims to describe research evidence supporting the use of ankle-foot orthoses to improve gait biomechanical outcomes among individuals with CP. Literature search was pursued from PubMed database. Studies were included if (1) they evaluated an outcome measure related with gait using ankle-foot orthotic (AFO) in children (2) considered children with a diagnosis of CP and have a (3) GMFCS classification of I, II or III. Papers were excluded if they evaluated (1) other population besides CP, (2) the use of orthoses other than AFOs and (3) gait analysis procedure was not presented. All the included studies have analyzed spatiotemporal parameters, the step length $(\mathrm{m})$, stride length $(\mathrm{m})$ and cadence (steps/minute) were the most frequently reported. Our findings showed that several studies have investigated the effects of AFOs, all of which have reported positive influences on at least one gait parameter, as well as positive changes in joint kinematics and kinetic in children with CP.
\end{abstract}

\section{Introduction}

Cerebral Palsy (CP) is an umbrella term used to describe children with a group of disorders associated with injury in the developing brain [1]. This brain injury affects posture and the control of movement in different parts of the body, resulting in specific topographic classifications, such as quadriplegia, hemiplegia and diplegia [2]. It has been reported that in Europe the incidence of CP ranges from 1.5 to 3 per 1000 living births[1].

Motor impairment is a hallmark of CP [2]. Spasticity, muscle weakness and decreased selective motor control, often cause limitations in mobility and activities of day living like walking. These limitations, which limit patient's ability to walk [1,3], impact families and - without proper adaptations - may lead to restricted participation in daily life, affecting social relations and education $[4,5]$. 
Walking limitations are related to some deformities, including weak plantar flexors or gluteal muscles, or even crouched gait with excessive hip and knee flexion, hence correction of these deformities may be particularly important. There are many physical therapy techniques used to correct these lower limb deformities [6]. For example, controlling crouched gait with increased hip and knee flexion and ankle dorsiflexion in stance phase in children is better done using an ankle foot orthoses in ambulatory. It is suggested that this system is a commonly intervention in children with $\mathrm{CP}$, and can improve joint stability, posture, and gait skills [6,7]. Therefore, studies have shown that to improve gait and reduce walking limitations, children with $\mathrm{CP}$ might use ankle foot orthoses (AFOs) $[1,3,4,6,7]$. Some studies on the literature evaluating the effects of AFOs on gait in children with CP generally report improvement in gait parameters, like spatiotemporal parameters, joint kinematics and kinetics, and knee extension [3,6]. The three-dimensional (3D) gait analysis is considered to be an important tool for the assessment of the results of clinical interventions in children with CP. These children usually exhibit functional limitations due to excessive muscle weakness, abnormal joint kinetics and abnormal postural reactions [2].

The use of an AFO imposes a mechanical constraint on the ankle, either to compensate for loss of function or to counteract an excess of function [4]. An AFO therefore acts by applying control to the ankle and foot and, dependent on its design, it can indirectly stabilize the knee and hip joints [4]. As such, AFOs aim to improve, i.e. normalize joint kinetics, joint kinematics and spatiotemporal parameters $[4,8]$.

Nevertheless, the functional abilities and challenges of children with $\mathrm{CP}$ are currently classified based on gross motor activities - such walking and siting (GMFCS); and the interaction between the body, the individual and the environment (ICF Core Sets for CP) [2,9]. The Gross Motor Function Classification System for Cerebral Palsy (GMFCS) classifies children with CP based on age $(0-2,2-4,4-6,6-12$ and 12-18 years) and respective functional levels [2,10]. Children classified as Level I can walk without restrictions, but tend to be limited in more advanced motor skills, whereas children classified as Level $\mathrm{V}$ are very limited in their ability to walk, even with a gait-assistance device [2]. The GMFCS is an extremely important tool for physical therapists who work with children with CP, as it allows to establish adequate therapeutic goals based on patient's age and motor level [2]. Further this tool also offers a common language because it coincides with the International Classification of Functioning, Disability and Health (ICF) and provide an environmental perspective highlighting the importance of social and personal factors such as preferences, interests, and motivation in these children's [10].

The purpose of this review was to describe research evidence of functional and biomechanical outcomes in gait supporting the use of AFO in children with cerebral palsy. The intent of this review was to focus on the major outcomes related to gait, such as kinetic and kinematic outcomes and spatiotemporal parameters. Additionally, components of the orthoses are presented.

\section{Materials and Methods}

2.1 Search strategy. A comprehensive literature search of articles was performed using PubMed database and limited to articles published between 2012 until November 2016. This research was motivated by a study of Amanda et al. [14] that aimed to find evidence of supporting clinical recommendation for AFO prescription and examine common limitation in AFO research methodology for individuals with neuromuscular disorders in respect to gait and functional mobility. Therefore, this study highlights the need to provide detailed information of participants and design features of AFO intervention. Standardized outcome measures related to the prescription goals and patient's functional mobility was also described as essential to determine whether the orthotic effect is beneficial [14]. In that way, the conducted systematic review was made only from January 2012.

The search was performed using the following keywords: Lower limb orthoses, lower limb orthosis, lower limb orthotics, AFO, gait, CP and ICF. The combinations used were the succeeding: [Lower limb orthoses and gait and cerebral palsy], with a result of thirty articles $(\mathrm{N}=30)$; [Lower limb orthosis and gait and cerebral palsy], with a result of twenty eight $(\mathrm{N}=28)$ articles but only three new; [Lower limb orthotics and gait and cerebral palsy], with seven articles $(\mathrm{N}=7)$ found and only two 
new; [AFO and gait and cerebral palsy], with a result of sixteen articles $(\mathrm{N}=16)$ and at least seven new; the last combination of key words were [gait and cerebral palsy and ICF], with a result of five $(\mathrm{N}=5)$ articles. The search strategy was developed in accordance with the recommendations of the Preferred Reporting Items for Systematic Reviews and Meta-Analyses (PRISMA) guidelines [15].

2.2. Eligibility Criteria. All articles retrieved from the search were compared against our inclusion and exclusion criteria. Studies were included if (1) they evaluated an outcome measure of gait relating to AFO use among children (0-18 years) (2) who had a diagnosis of CP and have a (3) GMFCS classification of I, II or III. Excluded if they evaluated (1) other population besides CP, if they (2) evaluating the use of orthoses other than AFOs and if they (3) haven't gait analysis procedure.

2.3. Data extraction and quality appraisal. The selected studies were independently reviewed and the following data were extracted: (1) Study design; (2) Demographic data, including sample size and age; (3) Diagnosis of CP and the GMFCS score; (3) Information relating the AFO intervention (type and material of the orthoses used); and (4) the outcome measures related to gait, in particular, kinematic and kinetic gait analysis and spatiotemporal parameters.

Studies included in this systematic review were significantly diverse in terms of study's design, subsequently the application of conventional scales assessment study quality fails to evaluate the studies adequately. Therefore, a new search was made to try to identify a valid and reliable grading system to evaluate study's quality in more detail. However the evaluation of the available scales assessment, none of them could be indicated to be considered for this systematic review. Even though, an effort was made to qualify the articles of this review. The assessment tool chosen was the critical appraising skills programme (CASP) checklist (Appendix I), which contains ten questions designed to be used as educational tools. These questions are divided in three sections: section A, B and C and the answer for them can be yes, no or can't tell. Section A concerns the evaluation of the results, as valid or not; Section B concerns the description of results; and finally, section $\mathrm{C}$ concerns the reproduction of the studies. Therefore14 included studies were included and are represented in TABLE 1 . The majority of studies were comprehended by the section $\mathrm{C}$, with only three studies $[3,4,16]$ that comprehended the section A. The worst classification assessment was the study of Danino et al. [16] and the better was the study of Ehab and colleagues [6].

Table 1: Critical Appraisal Skills Programme (CASP) checklist items.

\begin{tabular}{lccccccccccc}
\hline \multirow{2}{*}{ First Author } & \multicolumn{1}{l}{ Questions } & \multicolumn{1}{c}{ 2 } & 3 & 4 & 5 & 6 & 7 & 8 & 9 & 10 & Section \\
\hline Kerkum et al. [4] & Y & Y & C & C & Y & N & N & Y & Y & Y & A \\
\hline Meilahn et al. [13] & Y & Y & C & C & Y & Y & C & Y & N & Y & C \\
\hline Ehab et al. [6] & Y & Y & C & C & Y & Y & Y & Y & N & Y & C \\
\hline Jagadamma et al. [1] & Y & Y & C & C & N & Y & Y & Y & N & Y & C \\
\hline Danino et al. [16] & N & N & - & - & - & - & - & - & - & - & A \\
\hline Kerkum et al. [3] & Y & Y & C & C & N & Y & N & Y & Y & Y & A \\
\hline Kerkum et al. [17] & Y & Y & C & C & N & Y & Y & C & N & Y & C \\
\hline Khamis et al. [12] & Y & Y & C & C & N & Y & N & Y & N & Y & C \\
\hline Tishya et al. [8] & Y & Y & C & C & Y & Y & Y & Y & N & Y & C \\
\hline Wahid et al. [18] & Y & Y & C & C & Y & N & N & Y & N & Y & C \\
\hline Choi et al. [19] & Y & Y & C & C & Y & Y & N & Y & N & Y & C \\
\hline Danino et al. [20] & Y & Y & C & C & N & N & Y & Y & Y & Y & C \\
\hline Kerkum et al. [7] & Y & Y & C & C & N & Y & Y & Y & N & Y & C \\
\hline Schmid et al. [21] & Y & Y & C & C & Y & Y & Y & Y & Y & Y & C \\
\hline
\end{tabular}

Y: Yes; N: No; C: Can't tell. 


\section{Results}

3.1. Search yield. The initial literature search found over 86 published articles (Figure 1). After removing duplicates a total of 47 articles were retrieved. However, 2 articles were excluded for not being available to access and 6 excluded by reviewing the titles and abstracts. Following the application of predefined inclusion and exclusion criteria, 14 full-text reports were included in the systematic review, and these are summarized in detail in Table I and Table II. The studies varied widely in terms of study design, age of patients, CP type, orthoses devices and in gait outcome measures.

3.2. Study Design and size. The fourteen studies included varied a lot in terms of study design. One of them was a randomized controlled trial but the [6]majority are experimental studies $[3,4,7,17,21]$.

Sample sizes ranged from 1 participant in a case study [12] to $97 \mathrm{CP}$ patients [16]. The majority of the studies consisted of a sample lower than 20 participants and it is possible that many studies were underpowered to detect effects of AFO intervention in gait outcome measures [13].

3.3. Participant demographic profile. The average of age of participants was between 8 to 12 years? In two studies a maximum of 18 years old participant was found [12,18]. In another one a minimum of 3 years old participant [16] was evaluated. Most of the studies provided a mean age and range with standard deviation values.
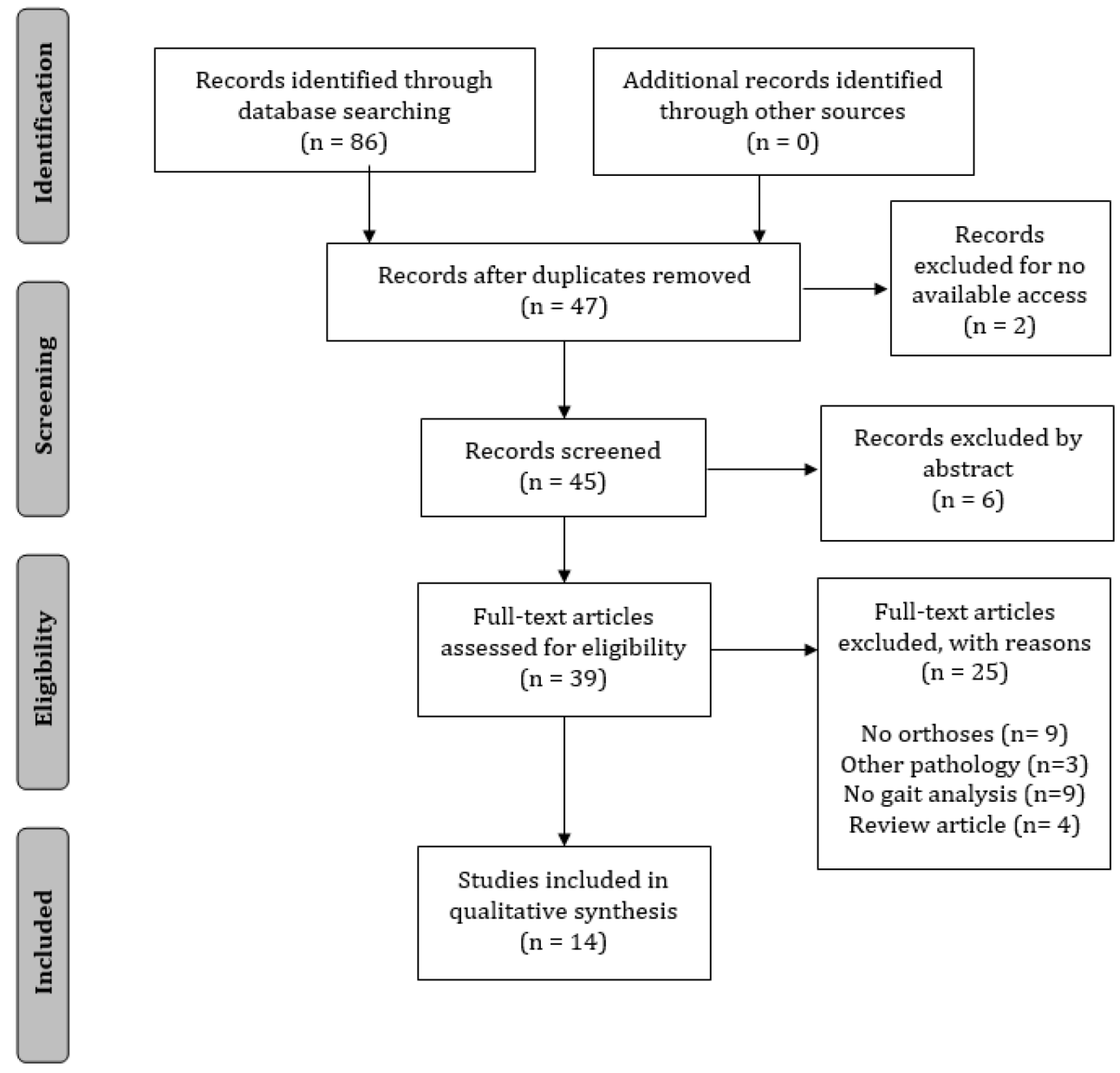

Figure 1: Flow diagram detailing the literature search and selection process [15].

3.4. Diagnosis of CP and the GMFCS score. The diagnosis and description of CP was generally made and included topographical descriptions of CP (hemiplegia, diplegia, quadriplegia). Only one study did not mentioned the type of CP [8]. A tendency was noted on the majority of studies regarding the description and stratification of patients by the GMFCS. There was only one study that did not report GMFCSt [1]. The levels of GMFCS ranged from level I to III. 
It is suggested that patients at GMFCS levels IV and V are reported separately of those at levels I to III, because these groups have a marked difference in locomotor prognosis and functional goals [9]. Therefore only patients between the level I to III at GMFCS can walk alone without any walking aid, are capable of doing a gait analysis test [4] and may be also cognitively able to understand and follow instructions [6].

3.5. Information relating the AFO intervention. The selected studies presented the description of AFO intervention as often poor and little detailed $[16,18,20]$. This means that the information about the type of orthoses in the study and whether the orthosis was custom made and fabricated or purchased was not clear. Also, the materials that made up the orthosis weren't detailed and sometimes weren't even mentioned by the authors $[16,18,20]$. Given the fact that the studies poorly identified the characteristics of the orthosis, it is not surprising that the instrumentation and materials involved in the fabrication of the orthosis wasn't exposed $[16,18,20]$. Although, a few studies $[3,4,7,17]$ revealed that the custom made AFO was from prepreg carbon fibers. The majority of studies used a costume made AFO build by an orthotist $[1,8,6,19]$ in cooperation with a physical therapy $[8,6,13,19]$. Further, two studies innovated on the intervention with AFO by adding a functional electrical stimulation (FES) device to the AFO. The first study, performed by Meilahn et al. [13] replace the AFOs of the children by a transcutaneous peroneal nerve stimulation neuroprosthesis designed to address footdrop with stimulation of the common peroneal nerve, which innervates the tibialis anterior and other muscles that produce dorsiflexion of the ankle. Secondly, a study by Khamis et al. [12] used a FES device which delivers electrical stimulations to the common peroneal nerve, hamstrings and quadriceps muscle with the aim of induce knee extension at the appropriate time and exact duration. Another study from Ehab et al. [6] used a custom fabricated strapping system named TheraTogs ${ }^{\mathrm{TM}}$ simultaneously with AFO to reduce excessive femoral anteversion and facilitate hip lateral rotation.

3.6. Outcome measures. The literature provided many biomechanical outcome measures related to gait, as well as kinematic and kinetic parameters and also spatiotemporal parameters. All the studies have analyzed spatiotemporal parameters, with the more recurrent parameters being step length $(\mathrm{m})$, stride length $(\mathrm{m})$, cadence (steps/minute) and walking speed $(\mathrm{m} / \mathrm{min})[1,4,16,12,18,20,21]$. Some parameters like step time, single and double support time, stance and swing time were also present in a few studies $[3,8,18]$. In respect to kinematic and kinetic data, only two studies $[4,18]$ didn't investigate one of these parameters. The kinetic data was very restricted in the studies with only one third, $[3,7,8,17]$ of the studies investigating this parameter, like the hip, knee and the ankle moment $(\mathrm{Nm} / \mathrm{kg})[1,8,17]$. In the other hand kinematic analysis was often considered, like the knee flexion and extension angle $\left({ }^{\circ}\right)[3,8,17,19]$ and also the dorsiflexion ROM of the ankle [8,12,19-21]. Nevertheless some studies also considered others outcomes, like functional outcomes related to daily activity and participation of the children, like Children's Assessment of Participation and Enjoyment (CAPE), [4,13,12] physical examination by physical therapist $[4,16,17,12,21]$ and even outcomes related to the AFOs satisfaction $[4,13,12]$ and others more specific measures related to the specific aim of the studies, summarized in "other parameters" at table II and table III.

3.7. Study Characteristic. A randomized control trial from [6] which included 57 children with CP was conducted to evaluate the effectiveness of a static ground reaction AFO and strapping system on improving gait parameter. This study was divided in three different groups. Children in group A performed the training program without any orthotic management, group B with the TheraTogs ${ }^{\mathrm{TM}}$ strapping system, and group $\mathrm{C}$ with the TheraTogs ${ }^{\mathrm{TM}}$ strapping system and static ground reaction ankle foot orthoses. The results were statistically significant among the groups in gait speed, cadences and stride length, being group $\mathrm{C}$ the one that obtained the best results.

A case series study from Choi et al. [19] investigated the impact of two different AFO on gastrocnemius operating length during walking in 11 children with CP. Gait analyses were performed and there was significant variability between participants and orthoses, however changes in gastrocnemius operating length were related to changes in ankle and knee kinematics during gait, with greater reductions among the GMFCS. 
Danino et al. [16] in a retrospective study assessed the effect of AFO on the foot progression angle (FPA) of 97 children with CP. AFOs improved gait, as reflected by improved temporal parameters, but they also increased internal rotation of the feet for mid-stance and mid-swing. AFOs did not produce any noteworthy differences between walking barefoot and walking with the brace in the hemiplegic group in what concerns FPA.

A retrospective analysis of 53 studies on children with CP from Danino et al. [20] found that significant differences were found between the barefoot condition and the AFO conditions for temporal and kinematic parameters during gait. Although, it was found that this improvement wasn't reflected by gait indices like the Gait Deviation Index (GDI) and others.

The effects when tuning of the AFO - Footwear Combination (AFO-FC) was investigated in an exploratory trial from Jagadamma et al. [1] on the gait of 8 children with CP. Comparisons were carried out for selected gait parameters in barefoot, non-tuned AFO-FC and tuned AFO-FC, with significant results for tuned AFO-FC in reduction of peak knee extension and knee ROM during gait.

To investigate whether specific gait parameters in children with $\mathrm{CP}$ would change within an acclimatization period after being provided with new AFO a study from Kerkum and colleagues [3] was performed. They found that in 10 children with CP over the course of four weeks, no significant differences were observed of any investigated parameter.

Kerkum et al. [17] investigated the effects of varying AFO stiffness on gait biomechanics and efficiency in 15 children with CP who walk with excessive knee flexion in stance. They found out that when compared to shoes only, all ventral shell spring-hinged AFOs improved the knee angle and decrease the net energy cost.

A pre-post experimental study from Kerkum et al. [4] evaluated the effect of floor reaction orthotic (FRO) optimized for ankle stiffness on the walking energy cost in 32 children with CP, compared to walking with shoes alone. The evaluated parameters were: walking energy cost, intensity of participation, daily activity, walking speed, gait biomechanics and the outcome measures of ICF.

Kerkum et al. [7] in a study with 15 children with CP prescribed with a hinged ventral shell AFO (vAFO) with adjustable stiffness realize that a decrease in net EC was found for walking with the optimized vAFO compared to shoes-only, daily activity remained unchanged and knee flexion I stance was reduced.

To evaluate the short and long term effects of FES to the quadriceps muscles in preventing crouch gait and achieving ankle plantar flexion, knee and hip extension at stance phase a study from Khamis et al. [12] was realized. In this study gait kinematics and spatiotemporal parameters with different devices was measured in a 18 -year-old boy diagnosed with CP.

A prospective, observational pilot study conducted by Meilahn et al. [13] in 10 children with $\mathrm{CP}$ replaced there $\mathrm{AFO}$, for correction of footdrop, with a transcutaneous peroneal nerve stimulation neuroprosthesis during 3 months. The tolerability and satisfaction were high, although 6 participants complained about the orthoses. Notice that fait velocity increased in $50 \%$ of the children studied.

Schmid et al. [21] investigated the effects of correcting lower extremity function by orthotics on spinal gait kinematics in $10 \mathrm{CP}$ patients and 15 healthy control group. The CP patients in both the barefoot and orthotic conditions indicated clinically relevant greater lumbar lordosis angles, smaller thoracic kyphosis angles and differences in frontal plane lumbar curvature angle compared to controls.

A multiple regression normalization (MR) by Wahid et al. [18] aimed to use this MR approach to identify the effect of a solid AFO on gait in 51 children with PC. Stride length, stance time, swing time and double support time were significantly different between children with $\mathrm{CP}$ and health controls using standard dimensionless equations.

To compare dynamic AFO (DAFOs) and adjustable dynamic response (ADR) AFOs a study by Wren et al. [8] was conducted in 10 children with CP. Children demonstrated better stride length, hip extension and swing-phase dorsiflexion in both braces versus barefoot. Push-off power and knee extension were better in ADR-AFOs than in DAFOs. 
Table 2: Study design, description of participants and details of the AFO interventions.

\begin{tabular}{|c|c|c|c|c|c|c|c|c|}
\hline \multicolumn{2}{|c|}{ Study } & \multicolumn{4}{|c|}{ Participants } & \multicolumn{3}{|c|}{ AFO Intervention } \\
\hline $\begin{array}{c}\text { First } \\
\text { Author }\end{array}$ & Design & $\mathrm{N}$ & Age & $\begin{array}{l}\text { CP } \\
\text { Type }\end{array}$ & GMFCS & Orthoses & Comparison & Material \\
\hline $\begin{array}{l}\text { Kerkum et } \\
\text { al. [4] }\end{array}$ & $\begin{array}{l}\text { Experimental } \\
\text { study }\end{array}$ & 32 & $6-14 y$ & $\mathrm{~S}$ & I; II; III & $\begin{array}{l}\text { Floor } \\
\text { Reaction } \\
\text { Orthoses }\end{array}$ & Shoes Only & $\begin{array}{l}\text { Custom made: Pre- } \\
\text { preg carbon }\end{array}$ \\
\hline $\begin{array}{l}\text { Meilahn et } \\
\text { al. [13] }\end{array}$ & Pilot study & 10 & $7-12 y$ & SH & I & $\begin{array}{l}\text { AFO with } \\
\text { FES }\end{array}$ & $\mathrm{AFO}$ & $\begin{array}{c}\text { WalkAide } \\
\text { neuroprosthesis }\end{array}$ \\
\hline $\begin{array}{c}\text { Ehab et al. } \\
{[6]}\end{array}$ & $\begin{array}{l}\text { Randomized } \\
\text { controlled } \\
\text { trial }\end{array}$ & 57 & $6-8 y$ & $\mathrm{SD}$ & I; II & $\begin{array}{l}\text { SGR-AFO } \\
\text { with } \\
\text { TheraTogs }\end{array}$ & $\begin{array}{l}\text { A: No orthotic; } \\
\text { B: TheraTogs; } \\
\text { C: TheraTogs } \\
\text { plus SGR-AFO }\end{array}$ & $\begin{array}{c}\text { TheraTogs }{ }^{\mathrm{TM}} \\
\text { strapping system; } \\
\text { Custom fabricated } \\
\text { SGR-AFO: Plastic }\end{array}$ \\
\hline $\begin{array}{c}\text { Jagadamma } \\
\text { et al. [1] }\end{array}$ & $\begin{array}{l}\text { Exploratory } \\
\text { trial }\end{array}$ & $\begin{array}{c}8 ; \\
11 \mathrm{c}\end{array}$ & $5-15 y$ & $\mathrm{D} ; \mathrm{H}$ & - & $\begin{array}{l}\text { Rigid AFO } \\
\text { with } \\
\text { optimally } \\
\text { cast Angle } \\
\text { of the } \\
\text { Ankle }\end{array}$ & $\begin{array}{c}\text { Barefoot } \\
\text { Non-tuned } \\
\text { AFO-FC } \\
\text { Tuned AFO-FC }\end{array}$ & $\begin{array}{l}\text { Custom made: } \\
\text { Polypropylene, } \\
\text { Ethyl Vinyl } \\
\text { Acetate and high } \\
\text { density plastazote }\end{array}$ \\
\hline $\begin{array}{l}\text { Danino et } \\
\text { al. }[16]\end{array}$ & $\begin{array}{l}\text { Retrospective } \\
\text { study }\end{array}$ & 97 & $3-16 y$ & $\begin{array}{l}\mathrm{SD} \\
\mathrm{SH}\end{array}$ & I; II; III & $\begin{array}{l}60 \text { Hinged } \\
\text { AFO (29 } \\
\text { Solid, } 7 \\
\text { Dynamic, } \\
1 \text { Posterior } \\
\text { spring leaf) }\end{array}$ & Barefoot & - \\
\hline $\begin{array}{l}\text { Kerkum et } \\
\text { al. [3] }\end{array}$ & $\begin{array}{r}\text { Experimental } \\
\text { study }\end{array}$ & 10 & $8-12 y$ & $\mathrm{~S}$ & I; II & $\begin{array}{c}\text { Ventral } \\
\text { shell AFO- } \\
\text { FC }\end{array}$ & Barefoot & $\begin{array}{l}\text { Custom made: Pre- } \\
\text { preg carbon }\end{array}$ \\
\hline $\begin{array}{l}\text { Kerkum et } \\
\text { al. [17] }\end{array}$ & $\begin{array}{l}\text { Experimental } \\
\text { study }\end{array}$ & 15 & $8-12 y$ & $\mathrm{~S}$ & I; II; III & $\begin{array}{l}\text { Ventral } \\
\text { shell } \\
\text { spring- } \\
\text { hinged } \\
\text { AFO }\end{array}$ & Shoes Only & $\begin{array}{l}\text { Custom made: Pre- } \\
\text { preg carbon fiber }\end{array}$ \\
\hline $\begin{array}{l}\text { Khamis et } \\
\text { al. [12] }\end{array}$ & Case study & 1 & $18 \mathrm{y}$ & $\mathrm{D}$ & II & FES device & $\begin{array}{l}\text { Ground Reaction } \\
\text { Ankle Foot } \\
\text { orthotics; Shoes } \\
\text { Only; Barefoot }\end{array}$ & $\begin{array}{l}\text { NESS L300 }{ }^{\circledR} \text { Plus } \\
\text { neuroprosthesis } \\
\text { system }\end{array}$ \\
\hline $\begin{array}{l}\text { Tishya et } \\
\text { al. [8] }\end{array}$ & $\begin{array}{l}\text { Randomized } \\
\text { crossover }\end{array}$ & 10 & $4-12 y$ & - & I; III & $\begin{array}{c}\text { DAFO } \\
\text { ADR-AFO }\end{array}$ & Barefoot & Custom made \\
\hline $\begin{array}{l}\text { Wahid et } \\
\text { al. [18] }\end{array}$ & $\begin{array}{l}\text { Multiple } \\
\text { regression } \\
\text { analysis }\end{array}$ & $\begin{array}{l}51 \\
34 \mathrm{c}\end{array}$ & $4-18 y$ & SD & I; II & Solid AFO & Barefoot & - \\
\hline $\begin{array}{l}\text { Choi et al. } \\
\text { [19] }\end{array}$ & Case series & 11 & $5-12 y$ & $\begin{array}{c}\mathrm{D} ; \\
\mathrm{H} ; \mathrm{Q}\end{array}$ & I; III & $\begin{array}{c}\text { DAFOs } \\
\text { ADR-AFO }\end{array}$ & Barefoot & $\begin{array}{l}\text { Custom made: } \\
\text { ADR-AFO } \\
\text { elastomer }\end{array}$ \\
\hline $\begin{array}{l}\text { Danino et } \\
\text { al.[20] }\end{array}$ & $\begin{array}{l}\text { Retrospective } \\
\text { analysis }\end{array}$ & 53 & $\sim 8 \mathrm{y}$ & SD & I; II; III & $\begin{array}{c}\text { AFO } \\
\text { (Solid, } \\
\text { Hinged, } \\
\text { Dynamic) }\end{array}$ & Barefoot & - \\
\hline $\begin{array}{l}\text { Kerkum et } \\
\text { al. [7] }\end{array}$ & $\begin{array}{l}\text { Experimental } \\
\text { study }\end{array}$ & 15 & $6-14 y$ & $\mathrm{~S}$ & I; II; III & $\begin{array}{c}\text { hinged } \\
\text { ventral } \\
\text { shell AFO }\end{array}$ & Shoes Only & $\begin{array}{l}\text { Custom made: Pre- } \\
\text { preg carbon fibers }\end{array}$ \\
\hline $\begin{array}{l}\text { Schmid et } \\
\text { al. [21] }\end{array}$ & $\begin{array}{l}\text { Experimental } \\
\text { study }\end{array}$ & $\begin{array}{l}10 \\
15 \mathrm{c}\end{array}$ & $\begin{array}{l}10- \\
17 y\end{array}$ & $\mathrm{SH}$ & I; II & $\mathrm{AFO}$ & Barefoot & Custom Made \\
\hline
\end{tabular}

S: Spastic; D: Diplegic; H: Hemiplegic; Q: Quadriplegic. 
Table 3: Summary of AFO effects on biomechanical and functional gait outcome measures.

\begin{tabular}{|c|c|c|c|c|}
\hline $\begin{array}{c}\text { First } \\
\text { Author }\end{array}$ & Orthoses & Kinematic \& Kinetic Parameters & $\begin{array}{c}\text { Spatiotemporal } \\
\text { Parameters }\end{array}$ & Other Parameters \\
\hline $\begin{array}{l}\text { Kerkum et } \\
\text { al. [4] }\end{array}$ & $\begin{array}{l}\text { Floor } \\
\text { Reaction } \\
\text { Orthoses }\end{array}$ & - & $\begin{array}{l}\mathrm{SL}(\mathrm{m}) ; \text { Step } \\
\text { width }(\mathrm{m}) ; \mathrm{C} \\
\text { (steps/min); }\end{array}$ & $\begin{array}{l}\text { Energy cost of walking test } \\
\text { (NN_EC\%SMC) (ECWT); } \\
\text { Daily activity with step } \\
\text { watch (steps/day); Children's } \\
\text { Assessment of Participation } \\
\text { and Enjoyment (CAPE); } \\
\text { Physical Fitness test } \\
\text { (VO2peak \& P20peak); } \\
\text { Physical examination; Intake } \\
\text { questionnaire; Function } \\
\text { Mobility Scale (FMS); } \\
\text { Functional Assessment } \\
\text { Questionnaire (FAQ); } \\
\text { Motivation diary; Goal } \\
\text { Attainment Scaling (GAS); } \\
\text { FRO properties satisfaction; } \\
\text { Goal Attainment Scaling } \\
\text { (GAS); }\end{array}$ \\
\hline $\begin{array}{l}\text { Meilahn et } \\
\text { al. [13] }\end{array}$ & $\begin{array}{l}\text { AFO with } \\
\text { FES }\end{array}$ & $\begin{array}{l}\text { Kinematic: Ankle dorsiflexion and } \\
\text { plantarflexion ROM }\left({ }^{\circ}\right)\end{array}$ & $\begin{array}{l}\text { Gait Velocity } \\
(\mathrm{cm} / \mathrm{s})\end{array}$ & $\begin{array}{l}\text { Daily-use diary; Subject } \\
\text { satisfaction of the device; } \\
\text { Participation in physical } \\
\text { activity; Number of falls; }\end{array}$ \\
\hline $\begin{array}{l}\text { Ehab et al. } \\
{[6]}\end{array}$ & $\begin{array}{l}\text { SGR-AFO } \\
\text { with } \\
\text { TheraTogs }\end{array}$ & $\begin{array}{l}\text { Kinematic: Knee and hip rotational } \\
\text { and flexion } \\
\text { joints angles }\left({ }^{\circ}\right) \text { in mid-stance }\end{array}$ & $\begin{array}{l}\text { Gait speed } \\
(\mathrm{m} / \mathrm{min}) ; \mathrm{C} \\
(\mathrm{steps} / \mathrm{min}) \\
\text { STL }(\mathrm{cm})\end{array}$ & 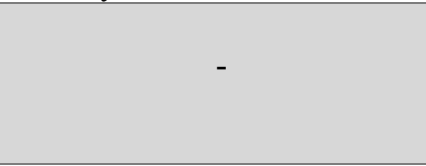 \\
\hline $\begin{array}{l}\text { Jagadamma } \\
\text { et al. [1] }\end{array}$ & $\begin{array}{l}\text { Rigid AFO } \\
\text { with } \\
\text { optimally } \\
\text { cast Angle } \\
\text { of the } \\
\text { Ankle }\end{array}$ & 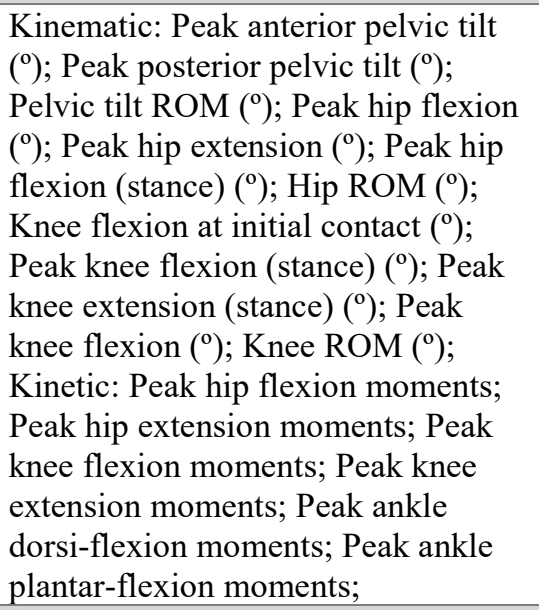 & $\begin{array}{l}\text { C } \\
\text { (steps/minute); } \\
\text { STL }(\mathrm{m}) ; \\
\text { Walking } \\
\text { Speed }(\mathrm{m} / \mathrm{s})\end{array}$ & - \\
\hline $\begin{array}{l}\text { Danino et } \\
\text { al. }[16]\end{array}$ & $\begin{array}{l}60 \text { Hinged } \\
\text { AFO }(29 \\
\text { Solid, } 7 \\
\text { Dynamic, } 1 \\
\text { Posterior } \\
\text { spring leaf) }\end{array}$ & $\begin{array}{l}\text { Kinematic: } \\
\text { Mid-stance }\left({ }^{\circ}\right) \text { : } \\
\text { Pelvic rotation; Hip rotation; Knee } \\
\text { rotation; } \\
\text { Mid-swing }\left(^{\circ}\right) \text { : } \\
\text { Pelvic rotation; Hip rotation; Knee } \\
\text { rotation; }\end{array}$ & $\begin{array}{l}\text { Walking } \\
\text { Speed } \\
(\mathrm{cm} / \mathrm{min}) ; \mathrm{SL} \\
(\mathrm{cm}) ; \mathrm{STL} \\
(\mathrm{cm}) ; \mathrm{C} \\
(\mathrm{step} / \mathrm{min})\end{array}$ & Physical Examination; \\
\hline $\begin{array}{l}\text { Kerkum et } \\
\text { al. [3] }\end{array}$ & $\begin{array}{l}\text { Ventral shell } \\
\text { AFO-FC }\end{array}$ & $\begin{array}{l}\text { Kinematic: SVA in MSt }\left(^{\circ}\right) \text {; Knee } \\
\text { flexion angle in }\left(\text { Midstance) MSt }\left(^{\circ}\right) \text {; }\right. \\
\text { Minimal knee flexion angle in Single } \\
\text { support phase }(\mathrm{SS})\left(^{\circ}\right) \text {; } \\
\text { Kinetic: Internal knee extensor } \\
\text { moment in MSt }(\mathrm{Nm} / \mathrm{kg}) \text {; Peak ankle } \\
\text { power }(\mathrm{W} / \mathrm{kg}) \text {; CoPexc }(\mathrm{mm})\end{array}$ & $\begin{array}{l}\text { Speed }(\mathrm{m} / \mathrm{s}) \\
\text { Single support } \\
\text { time }(\mathrm{s}) \\
\text { SL }(\mathrm{m}) \\
\text { Cadence } \\
\text { (step/min) }\end{array}$ & 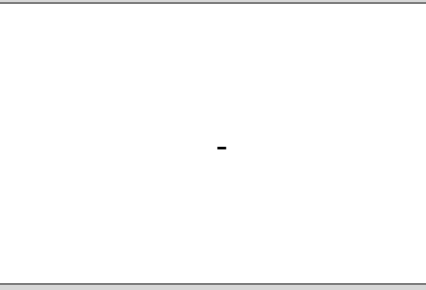 \\
\hline $\begin{array}{l}\text { Kerkum et } \\
\text { al. [17] }\end{array}$ & $\begin{array}{l}\text { Ventral shell } \\
\text { spring- } \\
\text { hinged AFO: }\end{array}$ & $\begin{array}{l}\text { Kinematic: Hip, Knee \& Ankle angle } \\
\left(^{\circ}\right) \text {; Ankle ROM }\left(^{\circ}\right) .\end{array}$ & $\begin{array}{l}\text { Walking } \\
\text { Speed } \\
(\mathrm{m} / \mathrm{min})\end{array}$ & $\begin{array}{l}\text { Physical Examination. Net } \\
\text { energy cost }(\mathrm{EC})(\mathrm{J} / \mathrm{kg} / \mathrm{m}) \text {; } \\
\text { Center of pressure excursion; }\end{array}$ \\
\hline
\end{tabular}




\begin{tabular}{|c|c|c|c|c|}
\hline & $\begin{array}{l}\text { Rigid; Stiff; } \\
\text { Flexible }\end{array}$ & $\begin{array}{l}\text { Kinetic: Hip, Knee \& Ankle moment } \\
(\mathrm{Nm} / \mathrm{kg}) \text {. }\end{array}$ & & \\
\hline $\begin{array}{l}\text { Khamis et } \\
\text { al. [12] }\end{array}$ & FES device & $\begin{array}{l}\text { Kinematic: Maximal knee extension } \\
\text { at midstance }\left({ }^{\circ}\right) \text {; Maximal knee } \\
\text { extension at the stance phase }\left(^{\circ}\right) \text {; } \\
\text { Maximal dorsiflexion at midstance } \\
\left(^{\circ}\right) \text {; Maximal dorsiflexion at the } \\
\text { stance phase }\left(^{\circ}\right)\end{array}$ & $\begin{array}{l}\text { Walking } \\
\text { Speed }(\mathrm{m} / \mathrm{s}) \\
\text { SL }(\mathrm{m}) ; \mathrm{C} \\
\text { (steps/min) }\end{array}$ & $\begin{array}{l}\text { Clinical Examination; Parent } \\
\text { satisfaction: Orthotics and } \\
\text { Prosthetics Users Survey } \\
\text { (OPUS); Pediatric Outcomes } \\
\text { Data Collection Instrument } \\
\text { (PODCI); }\end{array}$ \\
\hline $\begin{array}{l}\text { Tishya et } \\
\text { al. [8] }\end{array}$ & $\begin{array}{l}\text { DAFO } \\
\text { ADR-AFO }\end{array}$ & $\begin{array}{l}\text { Kinematic: Dorsiflexion mean in } \\
\text { stance }\left({ }^{\circ}\right) \text {; Dorsiflexion mean in } \\
\text { swing }\left(\left(^{\circ}\right) \text {; Knee flexion peak in }\right. \\
\text { loading response }\left({ }^{\circ}\right) \text {; Knee extension } \\
\text { peak in stance }\left({ }^{\circ}\right) \text {; Hip extension } \\
\text { peak in stance }\left(\left(^{\circ}\right) \text {; Pelvic tilt mean in }\right. \\
\text { stance }\left({ }^{\circ}\right) \\
\text { Kinetic: Dorsiflexion moment peak } \\
\text { in loading response }(\mathrm{Nm} / \mathrm{kg}) ; \\
\text { Plantar-flexion moment peak in late } \\
\text { stance }(\mathrm{Nm} / \mathrm{kg}) \text {; Plantar-flexion } \\
\text { power peak in push-off }(\mathrm{W} / \mathrm{kg}) ; \\
\text { Knee extension moment peak in } \\
\text { loading response, }(\mathrm{Nm} / \mathrm{kg}) ; \mathrm{Knee} \\
\text { flexion moment peak in mid-late } \\
\text { stance }(\mathrm{Nm} / \mathrm{kg}) ; \text { Hip flexion moment } \\
\text { peak in mid-late stance }(\mathrm{Nm} / \mathrm{kg}) ;\end{array}$ & $\begin{array}{l}\text { Velocity }(\mathrm{m} / \mathrm{s}) ; \\
\text { C (steps/min); } \\
\text { STL (m); } \\
\text { Double-limb } \\
\text { stance time } \\
\text { (\%GC); Step } \\
\text { time; SL; } \\
\text { Single-limb } \\
\text { stance time; }\end{array}$ & $\begin{array}{l}\text { Physical Examination; } \\
\text { Walking activity with step } \\
\text { watch (steps/day); Gait } \\
\text { Asymmetry; Standing } \\
\text { Balance; }\end{array}$ \\
\hline $\begin{array}{l}\text { Wahid et } \\
\text { al. [18] }\end{array}$ & Solid AFO & 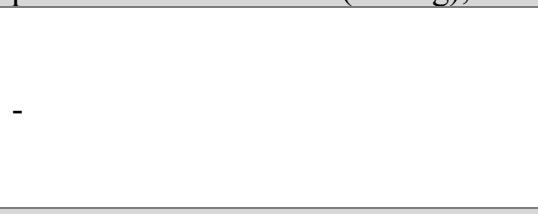 & $\begin{array}{l}\text { STL; C; Stance } \\
\text { time; Swing } \\
\text { Time; Double } \\
\text { Support; Step } \\
\text { time }\end{array}$ & - \\
\hline $\begin{array}{l}\text { Choi et al. } \\
{[19]}\end{array}$ & $\begin{array}{l}\text { DAFOs } \\
\text { ADR-AFO }\end{array}$ & $\begin{array}{l}\text { Kinematic: Knee Flexion Angle }\left(^{\circ}\right) \text {; } \\
\text { Ankle dorsiflexion angle }\left({ }^{\circ}\right) \text {; Peak } \\
\text { knee extension angle }\left(\left(^{\circ}\right) \text {; Peak ankle }\right. \\
\text { dorsiflexion angle }\left({ }^{\circ}\right) ;\end{array}$ & - & $\begin{array}{l}\text { Peak gastrocnemius length; } \\
\text { Normalized Peak } \\
\text { gastrocnemius lengthening } \\
\text { velocity; }\end{array}$ \\
\hline $\begin{array}{l}\text { Danino et } \\
\text { al. [20] }\end{array}$ & $\begin{array}{l}\text { AFO } \\
\text { (Solid, } \\
\text { Hinged, } \\
\text { Dynamic) }\end{array}$ & $\begin{array}{l}\text { Kinematic: Maximum knee } \\
\text { extension in stance \& swing; } \\
\text { Maximum ankle dorsiflexion in } \\
\text { stance or swing; }\end{array}$ & $\begin{array}{l}\text { Leg velocity } \\
(\mathrm{cm} / \mathrm{min}) ; \mathrm{SL} \\
(\mathrm{cm}) ; \mathrm{STL} \\
(\mathrm{cm}) ; \mathrm{C} \\
(\mathrm{step} / \mathrm{min})\end{array}$ & $\begin{array}{l}\text { Gillette Gait Index (GGI); } \\
\text { Gait Deviation Index (GDI); } \\
\text { Gait Profile Score (GPS); }\end{array}$ \\
\hline $\begin{array}{l}\text { Kerkum et } \\
\text { al. [7] }\end{array}$ & $\begin{array}{l}\text { hinged } \\
\text { ventral } \\
\text { shell AFO }\end{array}$ & $\begin{array}{l}\text { Kinematics: Peak knee extension } \\
\text { angle }\left(^{\circ}\right) \text {; Shank-to-Vertical Angle } \\
\left(^{\circ}\right) \text {; Kinetic: Peak ankle power } \\
\text { generation }(\mathrm{W} / \mathrm{kg})\end{array}$ & $\begin{array}{l}\text { Walking speed } \\
(\mathrm{m} / \mathrm{min})\end{array}$ & $\begin{array}{l}\text { Daily walking activity with } \\
\text { step watch (strides/day); }\end{array}$ \\
\hline $\begin{array}{l}\text { Schmid et } \\
\text { al. [21] }\end{array}$ & $\mathrm{AFO}$ & $\begin{array}{l}\text { Kinematic: Ankle plantarflexion at } \\
\text { IC; average ankle plantarflexion } \\
\text { during the stance and swing } \\
\text { phases; maximum ankle } \\
\text { plantarflexion during the swing } \\
\text { phase; }\end{array}$ & $\begin{array}{l}\text { Speed; C; SL; } \\
\text { Step time; }\end{array}$ & $\begin{array}{l}\text { Physical Examination; } \\
\text { Thoracic curves; Lumbar } \\
\text { curves; Pelvis segment; }\end{array}$ \\
\hline
\end{tabular}

\section{C: Cadence; SL: Step Length; STL: Stride Length.}




\section{Discussion}

Individuals with CP are characterized by impaired joint and muscle functions, deviations in the gait pattern and pain which leads to restrictions in their daily life [9,11]. These impairments need to be evaluated to understand how the health condition affects their routines [9] and how an orthotic prescription may help improve gait and functional independence.

The ICF Core Sets for children and youth with CP can be used to help understand patients' needs, to assess and report patient functioning in different settings, and also in intervention planning [9]. Notably, the ICF code el15 referring to "products and technology for personal use in daily living", which includes the ankle foot orthoses, it is considered one of the major environmental factors for $\mathrm{CP}$ and its included in all five develoed core sets for children aged 0 to 18 years, meaning that it plays an important role in daily life of children with CP.

An orthosis, like AFO is certainly a viable and useful physical therapy intervention tool for modulating biomechanical mal-alignment and poor postural control in children having CP [11]. Since one of the primary functions of an orthosis is to enable walking in those individuals with ambulatory capability, it is therefore a clinically relevant activity to evaluate [11]. Hence, this systematic review aimed to examine the effects of AFO interventions in respect to gait outcomes, like kinematic, kinetic and spatiotemporal parameters and also the changes in functional outcomes related to activity and participation of children with CP.

Usually impairment of children with $\mathrm{CP}$ are common evaluated by physical examination, $[4,16,17,12,21]$ although since the physical examination does not provide sufficient information on the patients' impairments, additional assessment of the gait pattern is warranted. Especially the use of 3D-gait analysis has proven to be a particularly powerful instrument to explicitly quantify the gait pattern in terms of joint kinematics and kinetics, and it can be used as a tool for clinical decision making, but also for orthosis evaluation [11].

Many studies used a standardized gait assessment with quantitative and objective outcome measures. These measures included spatio-temporal parameters and joint kinematics and kinetics $[4,6,13,17]$. Individuals with CP demonstrated improved gait with AFOs, such as improved in gait velocity and ankle kinematics, [13] cadence [6] and stride length [6,18] all of which reflect better walking abilities. [6] However, most AFOs reduced walking speed [17]. Another outcome measured by Kerkum et al. [4] was the physical fitness. This anaerobic test can provide a quantitative assessment of the improvement or declination in both children's condition and adolescents' with CP and has the potential to be an important measurement tool in clinical practice as well as in research work [22].

The AFO manufacturing and some compositions of it may be modifiable, such as the stiffness or the size of the hinge. In respect of the size of the hinge, it is dependent on the body weight and length of the patient, thus enhancing the importance of measure these variables in children $[4,17]$. Thereby, ankle stiffness can be adjusted within the same orthosis, using different spring forces towards plantar and dorsal flexion $[4,17]$.

Some studies $[4,6,13]$ shared the concern about the negative impact of wearing orthoses in children, such as: pain, discomfort, circulatory impairment [8] satisfaction with the orthosis $[4,13]$ and stiffness measured with the Bi-articular Reciprocal Universal Compliance Estimator (BRUCE), which is a recently developed device for measuring mechanical AFO properties $[3,4,17]$. Instructions of specific precautions to have with the orthoses were also given to the children and caregivers. The only adverse event reported by patients using a FES device was skin irritation caused by the electrodes [13].

As proposed by Harlaar et al. [23] the effects of lower limb orthoses on a patient's functioning also need to be evaluated at the activity level, expressing the gain for the patient. Most orthotic studies, however, predominantly evaluate the mechanical contribution of the orthosis to the wearer's gait [22]. Although these intervention related evaluations are important, they may not always be clinically relevant, and do not capture the patient's perspective, like the effects on standing and walking activities [11,23]. In this context, a study by Kerkum et al. [17] evaluated outcomes measures that are 
relevant in patient's daily life including, walking energy cost and daily activity. Using ankle foot orthoses during walking, as explained by Brehm et al. [24], resulted in a significant decrease in the energy cost of walking for children with cerebral palsy. This energy cost reduction was related to both a faster and a more efficient walking pattern, and changes of stance and swing phase knee motion $[4,6,24]$.

Other outcomes, like the intensity and enjoyment of participation assessed with Children's Assessment of Participation and Enjoyment (CAPE), patients personal goals measured assessed with Goal Attainment Scaling (GAS) and treatment adherence assessed with a motivation diary were also considered important outcomes [4]. A study performed by Meilahn et al. [13] also collected information from the caregiver and teacher about falls, and also completed a satisfaction survey that evaluated comfort and cosmetic of the device used [13].

As seen, AFOs are commonly evaluated in laboratory conditions $[1,4,8,16,17,12]$. This is a significant limitation because it doesn't capture the complexity of environmental factors encountered at home and within the community (i.e., stairs and ramps). It would be beneficial to include variations of these factors in the evaluation of gait.

Other limitation involved in some studies concerns the professional involved in AFO manufacturing [8,6,13,19] and gait analysis, [13] with only four studies mentioning the collaboration of a multidisciplinary team, like an orthotist, a physical therapist $[8,6,13,19]$ and an engineer [13].

\section{Conclusion}

Gait pattern is compromised in CP which can lead to activities limitations and participation restrictions. $[4,9,11]$. Orthoses AFOs might ameliorate deformities and improve gait pattern.

Our findings showed that the majority of studies introduced a costume made AFO build by an orthotist $[1,8,13,19]$ in cooperation with a physical therapy, $[1,8,13,19]$ although information about its composition and material was scarce $[3,4,7,17]$.

Several studies $[1,3,4,7,8,16,6,17-21]$ have investigated the effects of AFOs, all of them have reported positive influences on at least one gait parameter. However, there is a lack of consistency among the studies regarding which parameters were positively influence.

The results of this systematic review indicate that, AFOs influence temporal-spatial parameters and ankle joint kinematics of children with $\mathrm{CP}$ while others studies found changes in the proximal joint kinematics[1,3,7,8,17] as well as in functional outcomes related to daily activity and participation of the children $[4,12,13]$.

A study from Brehm et al. [11] suggested a core set of outcome measures for studying lower limb orthoses covering all levels of the ICF framework. Such a core set is also useful for the process of AFO stiffness optimization, and includes outcomes that quantify the AFO's effect on gait biomechanics, gait efficiency and daily walking activity [7].

However, to our knowledge no studies utilized the combination of the core set with the evaluation of the AFO. Only a few studies [5,12,13] consider the importance of studying the environmental and personal factors of the children with AFO, like the satisfaction, allergic reaction or others and also the comfort with the orthoses. Considering this lack of information, the different effects of AFOs on gait efficiency as reported in the literature might be partly explained by the personal and environmental factors and even by the AFOs mechanical properties, like the type of material, the coating and also the stiffness $[5,12,13]$.

Nevetheless, despite the frequent use of AFOs in CP, the prescription process of these orthoses is currently largely dependent on clinical experience, and prescription guidelines are scarce $[7,8]$. 


\section{Acknowledgments}

This research was supported by COMPETE 2020, from Agência Nacional de Inovação (ANI) - Projectos ID\&T Empresas em Copromoção, Programas Operacionais POCI and by the Fundação para a Ciência e a Tecnologia (FCT) and Centro2020 through the Project references: UID/Multi/04044/2013; PAMI - ROTEIRO/0328/2013 ( $\mathrm{N}^{\circ}$ 022158) and NEXT.parts - NextGeneration of Advanced Hybrid Parts with the reference n. ${ }^{\circ} 17963$.

\section{Disclosure of Potential Conflicts of Interest}

The authors indicated no potential conflicts of interest.

\section{References}

[1] Jagadamma KC, Coutts FJ, Mercer TH, Herman J, Yirrell J, Forbes L, et al. Optimising the effects of rigid ankle foot orthoses on the gait of children with cerebral palsy (CP) - an exploratory trial. Disabil. Rehabil. Assist. Technol. [Internet]. 2014;3107:1-7.

[2] Neto HP, Collange Grecco LA, Christovao TCL, Braun LA, Giannasi LC, Inoue Salgado AS, et al. Effect of posture-control insoles on function in children with cerebral palsy: Randomized controlled clinical trial. Bmc Musculoskelet. Disord. 2012;13:193.

[3] Kerkum YL, Brehm M-A, Van Hutten K, Van Den Noort JC, Harlaar J, Becher JG, et al. Acclimatization of the gait pattern to wearing an ankle-foot orthosis in children with spastic cerebral palsy. Jclb [Internet]. Elsevier Ltd; 2015;30:617-22.

[4] Kerkum YL, Harlaar J, Buizer AI, van den Noort JC, Becher JG, Brehm M-A. Optimising Ankle Foot Orthoses for children with cerebral palsy walking with excessive knee flexion to improve their mobility and participation; protocol of the AFO-CP study. BMC Pediatr. [Internet]. BMC Pediatrics; 2013;13:17.

[5] Bjornson, K. F., Zhou C., Stevenson, R. D. \& Christakis, D. (2014). Relationship of stride activity and participation in mobility-based life habits among children with cerebral palsy. Arch Phys Med Rehabil, 95(2), 360-368. https://doi:10.1016/j.apmr.2013.10.022.

[6] Abd El-Kafy EM. The clinical impact of orthotic correction of lower limb rotational deformities in children with cerebral palsy: a randomized controlled trial. Clin. Rehabil. 2014;28:1004-14.

[7] Kerkum YL, Harlaar J, Buizer AI, Van Den Noort JC, Becher JG, Brehm MA. An individual approach for optimizing ankle-foot orthoses to improve mobility in children with spastic cerebral palsy walking with excessive knee flexion. Gait Posture. Elsevier B.V.; 2016;46:10411.

[8] Wren TAL, Dryden JW, Mueske NM, Dennis SW, Healy BS, Rethlefsen SA. Comparison of 2 Orthotic Approaches in Children With Cerebral Palsy. Pediatr. Phys. Ther. 2015;27:218-26.

[9] Schiariti V, Selb M, Cieza A, O’Donnell M. International Classification of Functioning, Disability and Health Core Sets for children and youth with cerebral palsy: A consensus meeting. Dev. Med. Child Neurol. 2015;57:149-58.

[10] Palisano RJ, Rosenbaum P, Bartlett D, Livingston MH. Content validity of the expanded and revised Gross Motor Function Classification System. Dev. Med. Child Neurol. 2008;50:74450.

[11] Brehm M, Bus S, Harlaar J, Nollet F. A candidate core set of outcome measures based on the International Classification of Functioning, Disability and Health for clinical studies on lower limb orthoses. Prosthet. Orthot. Int. 2011;35:269-77.

[12] Khamis S, Martikaro R, Wientroub S, Hemo Y, Hayek S. A functional electrical stimulation system improves knee control in crouch gait. J. Child. Orthop. [Internet]. Springer Berlin Heidelberg; 2015;9:137-43.

[13] Meilahn JR. Tolerability and Effectiveness of a Neuroprosthesis for the Treatment of Footdrop in Pediatric Patients With Hemiparetic Cerebral Palsy. PM R [Internet]. Elsevier Inc.; 2013;5:503-9. 
[14] Chisholm AE, Perry SD. Ankle-foot orthotic management in neuromuscular disorders: recommendations for future research. Disabil. Rehabil. Assist. Technol. [Internet]. 2012;7:43749.

[15] Moher D, Liberati A, Tetzlaff J, Altman DG, Grp P. Preferred Reporting Items for Systematic Reviews and Meta-Analyses: The PRISMA Statement (Reprinted from Annals of Internal Medicine). Phys. Ther. 2009;89:873-80.

[16] Danino B, Erel S, Kfir M, Khamis S, Batt R, Hemo Y, et al. Influence of orthosis on the foot progression angle in children with spastic cerebral palsy. Gait Posture [Internet]. Elsevier B.V.; 2015;42:518-22.

[17] Kerkum YL, Buizer AI, Van Den Noort JC, Becher JG, Harlaar J, Brehm MA. The effects of varying ankle foot orthosis stiffness on gait in children with spastic cerebral palsy who walk with excessive knee flexion. PLoS One [Internet]. 2015;10.

[18] Wahid F, Begg R, Sangeux M, Halgamuge S, Ackland DC. The effects of an ankle foot orthosis on cerebral palsy gait: a multiple regression analysis C3. Eng. Med. Biol. Soc. (EMBC). Proc. Annu. Int. Conf. IEEE Eng. Med. Biol. Soc. [Internet]. 2015;5509-12.

[19] Choi H, Wren TAL, Steele KM. Gastrocnemius operating length with ankle foot orthoses in cerebral palsy. Prosthet. Orthot. Int. [Internet]. 2016;1-12.

[20] Danino B, Erel S, Kfir M, Khamis S, Batt R, Hemo Y, et al. Are Gait Indices Sensitive Enough to Reflect the Effect of Ankle Foot Orthosis on Gait Impairment in Cerebral Palsy Diplegic Patients? J. Pediatr. Orthop. [Internet]. 2016;36:294-8.

[21] Schmid S, Romkes J, Taylor WR, Lorenzetti S, Brunner R. Orthotic correction of lower limb function during gait does not immediately influence spinal kinematics in spastic hemiplegic cerebral palsy. Gait Posture [Internet]. Elsevier B.V.; 2016;49:457-62.

[22] Verschuren O, Ketelaar M, Keefer D, Wright V, Butler J, Ada L, et al. Identification of a core set of exercise tests for children and adolescents with cerebral palsy: A Delphi survey of researchers and clinicians. Dev. Med. Child Neurol. 2011;53:449-56.

[23] Harlaar J, Brehm M, Becher JG, Bregman DJJ, Buurke J, Holtkamp F, et al. Studies examining the efficacy of ankle foot orthoses should report activity level and mechanical evidence. Prosthet. Orthot. Int. 2010;34:327-35.

[24] Brehm MA, Harlaar J, Schwartz M. Effect of ankle-foot orthoses on walking efficiency and gait in children with cerebral palsy. J. Rehabil. Med. 2008;40:529-34. 